\title{
The Prebiotic Stage and the Evolution of Life on Earth
}

\author{
Gogu Ghiorghita $^{1} \&$ Gheorghe Surpateanu ${ }^{1}$ \\ ${ }^{1}$ Academy of Romanian Scientists, Spl. Independenței 54, Bucharest, Romania \\ Correspondence: Gogu Ghiorghita, Aleea Plaiului 8, Sc. E, apt. 92, Piatra Neamt, 610196, Romania. E-mail: \\ g.ghiorghita43@gmail.com
}

Received: April 19, 2019

Accepted: May 11, 2019

Online Published: May 16, 2019

doi:10.5539/enrr.v9n2p86

URL: https://doi.org/10.5539/enrr.v9n2p86

\begin{abstract}
The paper is a synthesis of the information collected so far on the origin and evolution of life on Earth. The life appearance and its evolution is correlated to matter evolution in univers: Big Bang, inorganic, organic, prebiotic, unicellular and multicellular stages. Concerning prebiotic stage in life evolution we present our theory based on syntone chemistry. Three syntones-methylene, nitrene and carbon monoxid carried by molecular nitrogen at law temperature could furnish the prebiotic bricks (sugars, lipids, proteins) at the contact to primary atmosphere components. Also, we think that these syntones could be considered as sources of great number of organic molecules. All organisms on Earth descend from a last universal common ancestor (LUCA). Two branches were derived from LUCA: one led to bacteria and the other to archaea and eukaryotes. The appearance of photosynthesis determined a transition from the oxygen-free atmosphere to the oxic atmosphere. Due to a series of endosymbioses, Eukaryotes emerged as organisms with nucleated cells and aerobic metabolism (which significantly increased the efficiency of cellular energy production). At about the same time appeared the first multicellular organisms. The paper also presents other important moments in the evolution of life on Earth, including the major biological crises in certain periods, resulting in the mass extinction of some groups of organisms. The evolution of the living world on Earth culminated with the emergence of man, the most complex being with language, superior thinking, emotions, creativity, etc.
\end{abstract}

Keywords: Origin of Life, Chemical Evolution, Syntone Chemistry, Prebiotic Compounds, Appearance and Life Evolution

\section{The Earth at Its Beginnings}

Ever since ancient times, man has been preoccupied with how life appeared on Earth, whether it was formed on it or brought from the universe, whether it is the work of divinity or the result of a long process of chemical evolution from inert matter, whether it is the prerogative of our planet or it is possible (in one form or another) on any planet in the Universe with Earth-like conditions, if it could be based on a chemical element other than carbon, etc. Although there has been a deeper understanding of our planet and of the living matter, there are aspects to which a definite, unanimous answer has not yet been found (Ghiorghita, 2009). We still do not have a coherent model of how life has appeared on Earth or how it could have been born on other planets (Cleaves, 2012). We are on an extremely intriguing "ground", populated with many ideas and many hypotheses, but few certainties.

Our planet was formed about 4.5 billion years $(\mathrm{Ga})$ ago and has gradually transformed, over hundreds of millions of years, from a hot gaseous mass into a solid body with a hot fluid core, being covered with a crust on the surface (made up of rocks and minerals) and bathed in a huge amount of water. The appearance of life on Earth was possible due to its dimensions and position with respect to the Sun, its orbit, located between "fire and ice," at a distance that allowed the maintenance of the planetary ocean in liquid state (Mader, 1990; Brack, 1991). Physical and chemical processes of condensation and accretion on early Earth would have occurred in an environment rich in $\mathrm{H}_{2}, \mathrm{CH}_{4}, \mathrm{NH}_{3}, \mathrm{CO}, \mathrm{H}_{2} \mathrm{~S}$ and $\mathrm{H}_{2} \mathrm{O}$. At first, the atmosphere of our planet would have been composed of hydrogen and helium, elements which, due to the lower gravity of Earth, were largely lost in space. The escape of hydrogen from the Earth's atmosphere has been overestimated (Bernstein, 2006). There are indications that the Earth's early atmosphere has long been reducing (Neuville, 2018). At the beginning, the gravity of Earth was low enough to retain hydrogen and helium, so these gases spread in the alien space. Subsequently, the "concentration" of the Earth due to its own gravity, the disintegration of the radioactive elements, the frequent meteoric bombardments, all caused intense volcanic activity. The celestial bodies, 
especially comets, enriched the Earth's primary atmosphere with various gases $\left(\mathrm{CO}_{2}, \mathrm{CH}_{4}, \mathrm{NH}_{3}, \mathrm{~N}_{2}\right)$ and water which, along with volcanic gases $\left(\mathrm{H}_{2}, \mathrm{~N}_{2}, \mathrm{~S}, \mathrm{Cl}_{2}, \mathrm{O}_{2}, \mathrm{SO}_{2}, \mathrm{CH}_{4}\right.$ etc., water vapours) contributed to the creation of a new atmosphere. Free oxygen was absent in this atmosphere, the ozone layer was also missing, so the Earth's surface was strongly exposed to UV radiation. The atmosphere was richer in carbon dioxide than at present, which ensured a high temperature on Earth. Due to this high temperature, the water on the early Earth was only in the form of vapours, forming thick and dense clouds, and condensing as the planet cooled and causing the water to fall in huge quantities on its surface, forming the planetary ocean (Mader, 1990).

The primary ocean would have had a high temperature at first, remaining warm for a long time. Its chemical composition in the Early Precambrian would have been different from the current one, with a much higher content of iron, calcium and manganese bicarbonates, and small (or no) phosphates. This composition would have been heavily influenced by the impact with meteorites and metal asteroids bombarding the Earth, which led to the increase of water concentration in certain elements and, at the same time, constituted into catalysts to the pre-biological chemical processes (Kremp, 1982). Approximately 3Ga ago, photosynthesis occurred, which caused a reduction in the amount of $\mathrm{CO}_{2}$ from the atmosphere, and so, the Earth avoided the fate of Venus, saving life at the same time (Mader, 1990). The oldest traces of life were found in hydrothermal vent precipitates (3.8 to $4.2 \mathrm{Ga}$ old), then in fossil deposits of thermal springs (about $3.5 \mathrm{Ga}$ old), stromatolites (about $3.45 \mathrm{Ga}$ old), which would indicate that biotic activity would have started on Earth now more than 4.2Ga ago (Neuville, 2018).

\section{Theories on the Origin of Life on Earth}

In J. P. Luminet's view (2014), life on our planet has emerged through a progressive process of complexation based on carbon chemistry, a process that should be universal and would take place in several phases: a) the cosmic stage, which began with the expansion of the universe (Big-Bang), the formation of stars, planets, carbon and heavy elements; b) the organic stage, in which the first hydrocarbon molecules that enter the structure of living matter appeared (substances discovered on other alien bodies such as comets, some meteorites, in the interstellar space, etc); c) the prebiotic stage, in which the "bricks" of life were formed: amino acids, proteins, nucleic acids; d) the primitive biological stage, which led to the appearance of unicellular bacteria, and e) the state of "intelligent" life, a stage of the evolved, complex life (Luminet, 2014).

If we make abstraction of the creationist theory, there have been three major theories about the origin of life on Earth. Two of them come from the ancient times: the theory of spontaneous generation and that of panspermia. The theory of spontaneous generation of life, formulated by Democritus and developed by Aristotle, accredits the idea that life comes from dead organic matter. This theory lasted for centuries, being invalidated as late as the 17th century through Fr. Redi's experiments and definitely ruled out by L. Pasteur's experiments in the 19th century (Ghiorghita, 2009).

The theory of panspermia or of the eternity of life sustains that life on Earth was "imported", coming from outside the planet, that its germs are present everywhere in the universe and reached Earth by various means. The ancient Greek philosopher Anaxagoras first advanced this idea, speaking of "seeds of live" from which all organisms are derived. He invented the term "panspermia," claiming that the universe is made up of an infinity of "sperm" (seeds) that came to Earth through rain and have yielded life forms. A follower of this theory in the modern age was S. Arrhenius, who considered life to be eternal, in the form of bacterial spores, capable of surviving in the interplanetary space, attached to the particles of cosmic dust and brought to Earth by the pressure of bright radiation (Arrhenius, 1903). In other authors' opinion, these spores would have been incorporated into the meteorites which fell on Earth, who would have provided them with some protection against low temperatures and radiation. Crick \& Orgel (1973) propose a more daring theory, the one of "directed panspermia", according to which intelligent beings would "inseminate" the Earth with organisms (life) brought from other planets. Even if we admit that the theory of panspermia is valid, the issue of the appearance of life in general is still not solved (Ghiorghita, 2009; El Albani et al., 2016).

Starting with the 1920s, more and more followers have adhered to the theory of abiogenesis, the origin of life on Earth through progressive chemical evolution from inorganic matter. The founders of the hypothesis of life

emergence through chemical evolution were Oparin (1924) and Haldane (1929), two biochemists who, independently of each other, imagined a similar scenario on the origin of life on our planet as a unique process with no geological traces. Some authors appreciate that, according to current knowledge, chemical evolution requires some conditions: reductive gas phase; alkaline $\mathrm{pH}$; freezing temperature; freshwater; dry/dry-wet cycles; coupling with high energy reactions; heating-cooling cycles in water; extraterrestrial intake of organic compounds and reaction products (Kitadai \& Maruyama, 2018). 


\section{On the Formation of Organic Compounds on Early Earth}

Oparin and Haldane started from the hypothesis that the prebiotic atmosphere of the Earth was strongly reducing, devoid of free oxygen and rich in carbon dioxide. Gases present in the Earth's primary atmosphere-methane, ammonia, hydrogen and water vapour, under the action of solar radiation and other energy sources, reacted with each other giving rise to simple organic compounds. In the absence of their oxidation and decomposition processes, over millions of years, these compounds accumulated in the water of the primary ocean, forming a so-called "hot diluted soup", as Haldane called it. The compounds thus formed spontaneously assembled into complex molecules such as proteins and nucleic acids under the conditions of the primitive Earth, which were completely different from the present ones. We know today that many biochemical reactions are carried out by enzymes, but this role could have been exerted by clays, the surface of minerals, thermal oscillations, etc. The macromolecules were then associated in structures capable of self-sustaining and self-reproduction.

Although Oparin and Haldane's scenario on the origins of Life on Earth were largely similar, there were some differences between the two concepts. While Oparin laid emphasis in his theory upon the generation of proteins in the primary ocean and primitive metabolic processes of heterotrophy type, Haldane attributed a primordial role to nucleic acids, and considered that the metabolism of the first forms of life would have been an autotrophic type. Later (1965), his interest in viruses led Haldane to be among the first to suggest that RNA might have had a central role in the origin of life (Tirard, 2017). The concept of primordial soup has somewhat simplified the problem of life emergence as an essentially unique event-the emergence of molecules, and then it all depended on chance, life being regarded as a "frozen accident" (Trefil et al., 2009).

At the beginning, the Oparin-Haldane hypothesis was met with reserve by specialists, but, in 1953, through Miller and Urey research, it received experimental support (Tirard, 2017). Miller designed a facility to simulate the ocean-atmosphere conditions of the early Earth. The authors appropriated Oparin's opinion that the primary atmosphere was reducing: it contained $\mathrm{CH}_{4}, \mathrm{~N}_{2}$, and traces of $\mathrm{NH}_{3}$, water and hydrogen. In a set of experiments (conducted in 1952), where a continuous mixture of water vapour, ammonia, methane and hydrogen (in some proportions) was subjected to continuous electric discharge between two electrodes (simulating lightning), Miller found that a number of organic compounds such as amino acids, hydroxy acids, simple aliphatic acids and urea were present in the condensation obtained. 11 amino acids were identified, of which 4 are proteinogenic. Some of the compounds identified were in significantly higher quantities (Miller, 1974). Miller and Urey (1953) published the results of these experiences in the Science journal, their work having a special echo in the scientific world (Laczkano \& Bada, 2003). Even though Miller and Urey are believed to have used the wrong atmospheric components (compared to the gases in the early Earth atmosphere) in their installation, their work highlighted the potential of non-enzymatic primordial chemistry (Trefil et al., 2009), giving rise to numerous experiments of this kind in various laboratories around the world. Using gas mixtures simulating the Earth's primary atmosphere and various energy sources (high temperatures, UV radiation, ionizing radiation, high energy particles, electric discharge, photosensitisers, shock waves, etc), these experiments demonstrated the possibility of obtaining various organic compounds: amino acids, organic acids, sugars, nitrogenous bases, fatty acids, formaldehyde, urea etc. (Garrison et al., 1951; Fox \& Harada, 1958, 1961; Oro \& Kimball, 1961a, 1961b; Robertson \& Miller, 1995; Kobayashi et al., 1989, 1990, 1997 etc.). Extensive information on such experiments, accompanied by comments and relevant considerations, is found in some recently published syntheses (Cleaves, 2012; Kitadai \& Maruyama, 2018).

The early Earth supply of organic matter would have been insured from two sources: an exogenous one-out of the planet; the other of terrestrial (endogenous) origin, the result of the chemical processes in the primary atmosphere and the primary ocean (Pascal et al., 2006; Cleaves, 2012). The contribution of the two sources depended on the amount of hydrogen in the atmosphere. Initially, under a high hydrogen level, things would have happened according to the Oparin-Haldane hypothesis. Substances present in the primary atmosphere: hydrogen, nitrogen, carbon monoxide and carbon dioxide, ammonia, methane, water vapour, sulphides (mainly from frequent volcanic eruptions), under the influence of special conditions existent about 3.8-4.1 billions of years ago (strong radiation, high temperatures, reducing conditions) combined with each other to form simple organic compounds. Subsequently, the hydrogen concentration in the atmosphere decreased, as a result of its escape into space. By default, the amount of organic molecules synthesized in the primary atmosphere was reduced, so that "feeding" the primary ocean with these molecules must have been more dependent on extraterrestrial sources.

A contribution of terrestrial origin might have come from hydrothermal organic syntheses in the presence of minerals (Pascal et al., 2006; El Albani et al., 2016). They represented chemically reactive environments that had favourable conditions for prebiotic synthesis. Baross and Hoffman (1985) sustain that the assumptions about the origin and the emergence of life should take into account the following aspects: the physical and chemical 
conditions necessary for the evolution of the sequence of chemical, biochemical, biological and ecosystem processes; a continuous source of energy to ensure these processes; an important biological source of elements associated with nitrogen-cycling reactions; the short time span between the formation of the planetary ocean and the first fossils of microorganisms. The authors believe that all these conditions were met in the Archean submarine hydrothermal systems (SHP). SHPs are widespread in tectonic or volcanic areas such as the mid-ocean ridges and have a major role in the movement of elements and energy between the interior and the Earth's surface. They would provide a $\mathrm{H}_{2} / \mathrm{CO}_{2}$ balance that would favour the synthesis of reduced carbon compounds. Within the hydrothermal vents, different temperature gradients are established, so they can provide areas that favour certain chemical reactions: in hotter areas, the synthesis of organic molecules, and, in the coldest areas, reactions of complex molecules, for example.

The hypothesis that these SHPs represented the source of life was first advanced by Corliss et al. (1981), who believed that the elements/bricks of life could be formed in submarine thermal springs, a hypothesis embraced and then developed by other authors (Russel et al., 1994; Martin \& Russell, 2003, 2005; Martin et al., 2008). Martin \& Russell trust that life occurred in marine areas with alkaline hydrothermal springs, where inorganic alveolar microstructures consisting of metal sulphide precipitates have been formed, a variety of micro-compartments prefiguring the functional precursors of cell walls and membranes of prokaryotes. These micro-compartments formed in the alkaline hydrothermal vent ensure the containment and concentration of the reaction products (the precursors of the bricks of life), preventing them from spreading into the ocean, catalysing the prebiotic organic syntheses at their internal surfaces. Inorganic barriers of interconnected microspores from deep-sea vents create natural protons gradients in alkaline hydrothermal systems. These barriers were composed of $\mathrm{Fe}(\mathrm{Ni}) \mathrm{S}$ catalytic minerals and played the role of enzyme-specific co-factors, which suggests the abiotic origin of the chemosmotic coupling (Martin \& Russell, 2007; Herschy et al., 2014).

It is believed that, in Hadean and Archean times, the oceans were devoid of oxygen and $\mathrm{CO}_{2}$ was much higher than at present, which would have favoured the reaction between $\mathrm{H}_{2}$ and $\mathrm{CO}_{2}$. Martin and Rusell (2013) propose an $\mathrm{H}_{2}$-dependent chemistry, with arsenic and bacterial-like reactions that use the Wood-Ljungdahl pathway of $\mathrm{CO}_{2}$ reduction leading to acetyl-CoA. Starting from the fact that $\mathrm{FeS}$ catalyses the synthesis of $\mathrm{CH}_{3} \mathrm{SH}$ from $\mathrm{CO}_{2}$ and $\mathrm{H}_{2} \mathrm{~S}$ and together with NiS catalyzes the synthesis from $\mathrm{CO}$ and methyl sulphide of thioester acetyl methyl sulphide, the authors consider that such syntheses could have occurred in the above mentioned microstructures. This concept is argued to be in agreement with the idea that the acetyl-CoA pathway of $\mathrm{CO}_{2}$ fixation could be the most primitive biochemical mechanism to reduce $\mathrm{CO}_{2}$. These catalytic compartments would have even been able to perform chemical syntheses similar to RNA-world, thus generating replication systems (Martin \& Russell, 2003). In the authors' view, the alkaline hydrothermal systems in the oceans would have become a kind of natural electrochemical reactors that generated a protometabolism that would lead to the emergence of life (Herschy et al., 2014). Hydrothermal vents are believed to have also represented an important atmospheric source of $\mathrm{NH}_{3}, \mathrm{CO}$, $\mathrm{CH}_{4}$ and $\mathrm{H}_{2}$ in the early Earth, but that their specific temperatures would have facilitated decomposition rather than the formation of organic compounds (Cleaves, 2012; Kitadai \& Maruyama, 2018).

Herschy et al. (2014) attempted to reproduce these conditions experimentally in a reactor and, by using thin-walled inorganic structures composed of $\mathrm{Fe}(\mathrm{Ni}) \mathrm{S}$ catalytic microcrystals, they virtually confirmed the possibility of generating simple organic compounds from $\mathrm{H}_{2}$ and $\mathrm{CO}_{2}$. Previously, Bernstein (2006) appreciated that early Earth was more actively tectonic than at present, and that hydrothermal vents provided reducing conditions that could favour organic synthesis, even better than gas-phase synthesis. In support of their opinion, they brought results of experiments to simulate the conditions of hydrothermal vents carried out by some authors, confirming the production of lipid-like compounds, the formation of amino acids and nucleotides and their oligomerization. However, Kitadai and Maruyama (2018) consider that, although Hadean Earth would have been able to synthesize amino acids from $\mathrm{NH}_{3}, \mathrm{HCN}$ and $\mathrm{H}_{2} \mathrm{CO}$ through rapid-heat-freezing cycles to prevent unwanted reactions, primitive hydrothermal submarine systems could not provide these conditions. They did not have the ability to produce amino acids in concentrations that sustained the chemical evolution of life. This conclusion is to be reflected upon if we consider that the oldest microfossil remains were found in the hydrothermal vent precipitates formed 3.8-4.2Ga ago. Neuville (2018) shows that the oldest material remains of life identified in some older sediments would correspond to prebiotic atmospheric chemistry.

There is more and more evidence that organic compounds "imported" from outside the Earth, also being transported by meteorites, asteroids, comets, micrometeorites (interstellar dust particles-IDPs), also contributed to the formation of the "organic soup" in the primary ocean. About $3.9 \mathrm{Ga}$ ago, the Earth was bombed by a real meteor shower, with the intensity of their fall being estimated at about 104 times higher, so they could have been an important source of compounds transferred to the primary ocean. Meteorites, especially those in the category of 
carbonaceous chondrites, contain significant amounts of organic matter (1-2\% of their mass), including: various hydrocarbons, carboxylic acids and dicarboxylic acids, amino acids, hydroxy acids, amines, polyols, fatty acids, nucleobases and other N-heterocycles etc., (Bernstein, 2006; Cleaves, 2012). Over 80 amino acids have been identified in carbonaceous chondrites, including 12 proteinaceous amino acids. Their abundance oscillates between 0.2 and 2400ppm (Kitadai \& Maruyama, 2018; Kee \& Monnard, 2016). In Murchison meteorite, for example, over 70 amino acids (racemic mixture), some purine and pyrimidine bases, fatty acids have been identified (Brack, 1991). The presence of these compounds in meteorites is an argument that they could be traced through geochemical processes on the Prebiotic Earth. It is also appreciated that a significant contribution of organic carbon has also been attributed to IDPs (up to $50 \%$ of their mass), especially under the conditions of primitive Earth (Bernstein, 2006). Comets are dust and ice mixtures and contain various inorganic and organic compounds. Much of the ocean water could come from comets. Among the organic compounds present in comets were identified $\mathrm{CH}_{3} \mathrm{OH}, \mathrm{CH}_{2} \mathrm{O}, \mathrm{HCN}, \mathrm{CH}_{4}$ etc. (Cleaves, 2012). Comets would contain 10 times more organic compounds than carbon-rich meteorites, and the amount of amino acids procured by comets could reach 10,000ppm (Kitadai \& Maruyama, 2018).

\subsection{The Formation of Prebiotic Compounds by Syntone Chemistry}

In previous papers (Surpateanu \& Lungu, 2011; Surpateanu, 2017) we proposed a new theory on the formation on Earth of the first proteinogenic amino acids and their corresponding polypeptides. In Figure 1 we present briefly the steps taken in their formation.

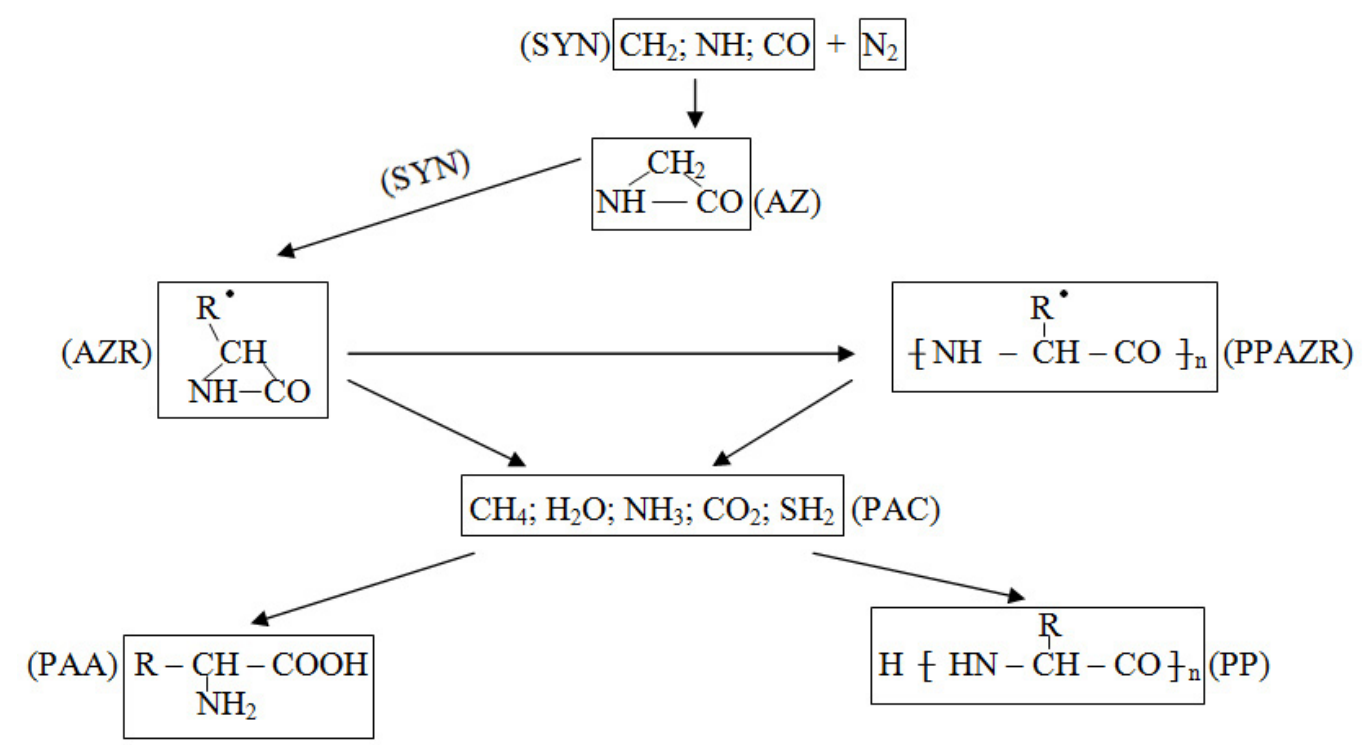

Figure 1. Formation of proteinogenic amino acids and corresponding polypeptides

(Syn-synthons, AZ-aziridinone, AZR-aziridinone radicals, PPAZR-aziridinone polypeptide radicals, PAC-primary atmosphere components, PAA-proteinogenic aminoacids, PP-polypeptides)

Three synthons-methylene, nitrene and carbon monoxide, stabilized as diazomethane, azotic acid and diazocarbonyl, first form, at very low temperatures, aziridinone. This undergoes an asymmetric induction at the nitrogen level, and furthermore, with the same three previously mentioned synthons, forms optically active aziridinone radicals of left configuration (AZR). These radicals can be polymerized by forming optically active polyradicals. All these transformations take place outside the Earth. The mixture of these precursors is always carried by molecular nitrogen, at low temperatures, which was probably brought by comets. Polarized light has played an essential role in all these asymmetric chemical transformations. Upon contact with the primary atmosphere components (PAC), the structures of the protein amino acids (PAA) and their corresponding polypeptides (PP) have been finalized. 
We note that the first polypeptides were formed from PPAZR precursors and not from proteinogenic amino acids. This can be explained by the fact that, in chemical synthesis, we cannot polycondensate amino acids in the aqueous environment. This is only reserved for protein biosynthesis processes.

As quantitative arguments in the presented theory we mention experimental results on the behaviour of methylene in the presence of water, carbon dioxide and ammonia when whole classes of organic compounds were obtained: alcohols, carboxylic acids and amino acids. We analyzed the chemical behaviour of methylene in contact with a) water, b) carbon dioxide in water and c) carbon dioxide, ammonia in water. Practically, diazomethane etheral solutions generated from nitrosomethylurea have been treated with previously mentioned mixtures, at $0-5^{\circ} \mathrm{C}$. Samples of reaction product mixtures have been obtained by removing the liquid fractions and 1H-NMR spectra and ESI-MS data have been recorded. For each contact between methylene and the components of the primordial atmosphere (previously coded as a, b and c), we identified the alcohols, carboxilic acids and amino acids respectively (Figure 2). For the amino acids the MS-spectra show $\mathrm{m} / \mathrm{z}$ maximum values of over 374 units.

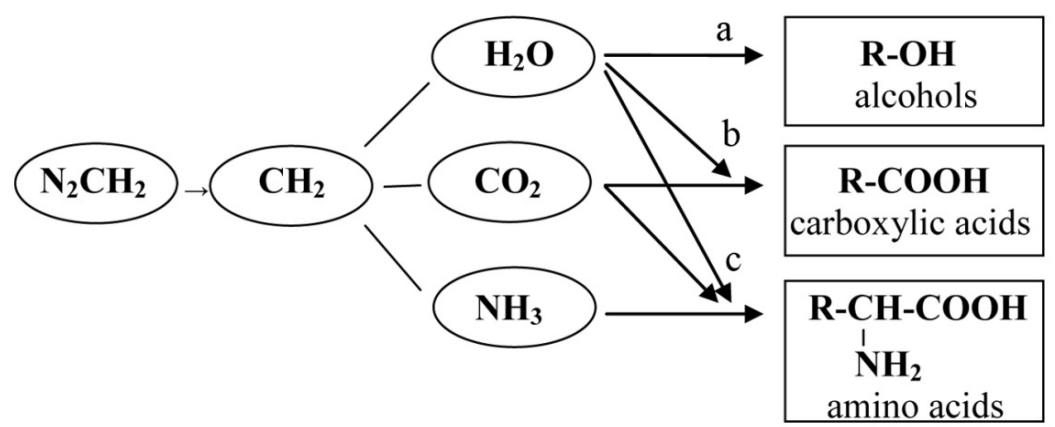

Figure 2. Formation of alcohols, carboxilic acids and amino acids

Based on a suitable method of obtention of methylene, for example from methane, it is possible to reach a large variety of organic compounds like alcohols, organic acids and amino acids by very simple experimental procedures. According to our results when studying the chemical behaviour of the three syntones (methylene, nitrene and carbon monoxide) before and during the interaction with the components of the primordial atmosphere we proposed an experimental assembly to obtain proteinogenic amino acids and polypeptides (Figure 3), (Surpateanu, 2017).

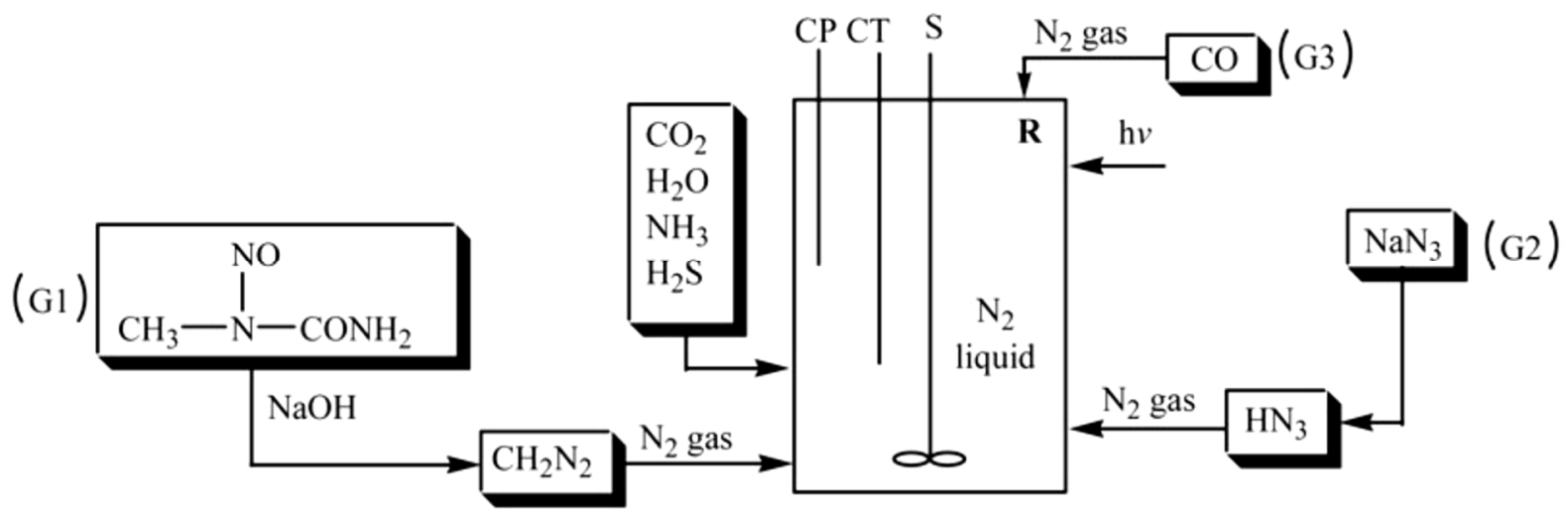

Figure 3. Experimental assembly

(The assembly contains a reactor $(\mathrm{R})$ equipped with a presure controller $(\mathrm{CP})$, temperature controller $(\mathrm{CT})$, stiring device (S) and inlets for three gas syntones carried by nitrogen)

As a starting compound gas for the synthesis of nitrosomethyl-urea (G1) we suggest methylene. For generating nitrene one can use sodium or potassium azides. Carbon monoxide is easily accessible. In this case we suggest its feeding from pressurized reservoir. The feeding lines G1, G2 and G3 must deliver ultra-pure-syntones to the reactor. Polarized light must be generated in side the quartz reactor. A cooling mantle using liquid nitrogen is 
needed to cool the light source. The quartz reactor should be filled initially with liquid nitrogen, which will become the reaction medium.

The syntones: methylene, nitrene and carbon monoxide are thermodynamic unstable in normal conditions but they are very reactive from chemical point of view. Generally, syntones are molecular fragments which could be formed in special conditions. Also, in this paper as syntones are involved the reaction intermediaries.

The Figure 1 previously presented was based on mechano-quantic simulations of chemical reactivity using DGauss with the B88-LYP GGA energy functional.

Finally, starting from the three synthons-methylene, nitrene and carbon monoxide, all components of prebiotic matter can be obtained: lipids, sugars, amino acids, proteins, etc. The thermodynamic conditions, the partners (stable molecules) offered to the synthon contact, the reaction environment, the influence of some external factors to the reaction systems (polarized light) are aspects belonging to the field developed by us, that of synthonic chemistry.

\section{Formation of Complex Organic Molecules and Macromolecules}

The question arises of the hypothetical favourable places (niches) on the early Earth that would have favoured the accumulation (concentration) of the organic compounds and the polymerization or polycondensation reactions. In the absence of enzymes, the catalysts of these reactions were probably "nongenetic" molecules, metal-ion complexes, short peptides, mineral formations or particles (Kee \& Monnard, 2016). Tidal pools, icy environments, mineral surface ( 4.5 to $4 \mathrm{Ga}$ ago, there were over 1,000 mineral species) would have been conducive to these processes (Kitadai \& Maruyama, 2018). Spontaneously or as a result of drying processes, amino acids and activated nucleotides could adhere and polymerize to the surface of some minerals (Kee \& Monnard, 2016). With the expansion of dry land, which led to the division of the ocean, small aquatic basins were formed, where organic compounds were concentrated, and repeated wetting/drying cycles, clays and minerals might have provided their polymerization. Favourable sites for these processes could be ocean volcanic areas and hydrothermal vents (Bernstein, 2006; Pascal et al., 2006). The pores generated in minerals that precipitate at the contact of heated water vents with the surrounding ocean water would ensure the concentration of organic compounds by thermophoresis (Baaske et al., 2007). Porous structures generated by mineral sulphides created the conditions of protometabolism and protected the first proto-organisms of "dilution and other damage" (Lambert, 2015). Deamer et al. (2006) believe that a more suitable environment for life emergence would be an aqueous phase with moderate temperature oscillations (below $60^{\circ} \mathrm{C}$ ), a pH close to neutral and very low (submillimolar) concentrations of divalent cations. These conditions would be ensured not by seawater but by fresh water pools formed by the rains fallen on the earliest volcanic land masses and small continents.

Starting from the fact that directional selection works on the principle of "increasing independence from the environment", Novikov (2012) considers that abiogenesis on Earth has gone through three stages: DNA world, RNA world and Protein world. The three stages depended on temperature and the absence/presence of water. Selection acted on both, abiogenesis-in terms of promoting the most stable macromolecules, and biogenesis-in order to promote organisms with a high degree of independence from the environment. Abiogenesis was carried out under dehydration conditions, and the energy source for chemical evolution on Earth was temperature (thermal factor). DNA world spread to almost the entire Hadean, under extreme conditions, when the temperature was high (DNA being the most stable macromolecule), RNA world appeared in the second half of Hadean and linked the anhydrous DNA world and the Protein world (in Archean) which require water (Novikov, 2012).

Throughout the DNA world, molecular selection of the most stable nucleotide sequences occurred, with GC sequences being more stable at high temperatures, which proves that the oldest organisms have GC type DNA.

In addition to higher stability, DNA also possesses catalytic activity. As the Earth's surface temperature dropped, RNA world appeared. At first, RNA had as DNA matrix, and then RNA served as a matrix for DNA. At this stage, prebiotic DNA and RNA molecules have acquired the ability to store genetic information. DNA and RNA have coacervated microsystems. Protocelules would have appeared in the RNA world stage and replicated in the presence of ribozymes, which acted in waterless conditions. When the temperature at the surface of the planet allowed the condensation of atmospheric water vapour $\left(100^{\circ} \mathrm{C}\right)$, Protein World appeared, when the biological evolution took the place of the abiogene one. Initially, protein synthesis was produced using small RNA molecules that catalyzed the formation of peptide bonds between amino acids. Subsequently, the catalytic function was taken over by the protein. Stable complexes were formed between polynucleotides and proteins (Novikov, 2012). 
According to a scenario on prebiotic molecular evolution, RNA would first appear on the evolutionary stage (RNA world), being a more flexible molecule than DNA (Woese et al., 1966). The "RNA first" scenario is based on the fact that RNA has an essential and multiple role in the metabolism of living organisms: the cells produce deoxyribonucleotides from ribonucleotides; (DNA-specific) thymine is derived by methylation of uracil (RNA-specific basis); RNA serves as primer in DNA biosynthesis; RNA can perform the function of catalyst, etc. There are reasons why DNA could be assimilated to a modified RNA to better preserve genetic information. RNA world would arise from a mixture of activated nucleotides (Pascal et al., 2006). It is considered unlikely that the current DNA/RNA/Protein system to have occurred accidentally from the abiotic mixture of amino acids and nucleotides on the early Earth and RNA is therefore supposed to have served both as a carrier of genetic information and capable of catalysis of its own molecules (Kitadai \& Maruyama, 2018). Orgel (quoted by Pascal et al., 2006) considers that the occurrence of self-replicating RNA sequences is less probable because the prebiotic pathway in the synthesis of nucleotides does not appear plausible. Consequently, RNA world would have been preceded by pre-RNA world, a molecule replication system in which peptides (PNA world = peptide nucleic acids) would both act as information carriers and catalysts. Life would have developed through a process of RNA-peptide co-evolution, proven by the preservation of the mechanism of translation of genetic information to this day. Some authors, however, doubt that early Earth conditions would have been in place for a functional RNA and advance the hypothesis that about 4 billion years ago, the information system of pre-cellular forms was based on $\beta$-sheet amyloid conformers, stable multifunctional, structural entities capable of self-replication and catalysis, and that amyloid world would have made the transition to the amyloid-RNA-protein world. The amyloid assemblages were prebiotic informational and protometabolic entities, having the ability to catalyze the formation of simple metabolites precursors (Maury, 2018).

As shown above, there is the "first metabolism" scenario, according to which the first steps to life would not require DNA, neither RNA nor enzymes, and that the first metabolic reactions would have been carried out with the help of minerals in the spaces of porous rocks filled with organic substances (primordial soup), as suggested by Oparin-Haldane. The emergence of life is conceived by some authors as a multistep process (of progressive chemical reactions), which began with the formation of small molecules acting in the network with sequences subjected to molecular selection, followed by cellularisation and the appearance of individual organisms subjected to natural selection of Darwinian type (Trefil et al., 2009). According to Novikov (2012), Protein world represented a revolution in abiogenesis, proteins/ enzymes having a highly superior RNA catalytic potential, substrate specificity in biochemical reactions and thus increased selectivity. With the appearance of pre-cellular structures, a higher degree of independence of biochemical reactions to the environment was produced, and the greater complexity of the biological system ensured an increased influence of the mutations on the phenotype and, implicitly, an increased efficiency of natural selection.

Life cannot be conceived without the presence and interaction of the two major categories of macromolecules, nucleic acids and proteins, separated from the environment through a lipid membrane, a mechanism that ensured the growth, reproduction and perpetuation of the system, its evolution to complexity under the natural selection. Because DNA is a more complex structure than RNA, we tend to believe that at first, in the precellular stage of life, RNA possessed genetic information, exerted the function of a catalytic agent in protein generation, had self-replication capacity, but was not a sufficiently stable product (it was a flexible molecule, which probably gave it an advantage at first). Subsequent DNA, with the double-stranded structure (possibly arising from such RNA), became a more stable macromolecule, possessing genetic information, easily replicating, etc., taking over the task of conducting cellular activity, fulfilled task but through RNA. Although some authors have a different opinion, we do not exclude the possibility that the three basic cellular "actors", DNA, RNA and protein-have appeared concurrently, interacted with each other and underwent a co-evolution process in which each has gradually acquired the role it currently holds.

\section{Pre-Cellular Forms of Life}

Partitioning is an important attribute of the living matter, which ensures parallel reactions in spaces and in a distinct manner, controlling the exchanges between the living and the environment, etc. After the formation of organic molecules on Earth, mechanisms were needed to bring them into close proximity and spatially separate them from the environment. Quoting a number of authors, Monnard and Walde (2015) show that several types of molecular aggregates have been imagined that can perform this role: "self-organized entities of congealed organic matter"; coacervates; proteinoids (microspheres); organic hydrogels; aggregates of lipidic amphiphiles, amphiphilic peptides, or mixtures of these, etc. Vesicular compartments appear to best mimic the structural and functional properties of precellular systems. 
Returning to Oparin's theory, organic compounds formed in the primary ocean, consisting of proteins, lipids, carbohydrates, nucleic acids, aggregated into colloidal, "coacervated" colloidal particles (precocious structures) surrounded by a water molecule. They had some properties specific to the protoplasm, they could selectively incorporate substances from the environment, they had a primitive metabolism (heterotroph type) and the ability to grow and divide (Oparin, 1960). Only the presence of DNA in these formations was necessary to transmit their characteristics to the descendants, a process that some coacervates probably had attained, turning into protobionts (El Albani et al., 2016). Oparin-Haldane's heterotrophic theory raised interest and was accepted because, experimentally, the possibility of prebiotic synthesis of organic products under reduced conditions was demonstrated, but also because a heterotrophic organism is simpler than a heterotroph (Laczkano \& Miller, 1996). Towards the end of his life, Oparin realized he was wrong by concentrating on colloid theory and neglecting liposomes. Despite the limitations of his theory, Oparin is part of the gallery of the great scholars of the last century by establishing the concept of early molecular evolution (Kolb, 2015). His proposed scenario on the origin of life on Earth would have led many contemporaries to think, imagine, experiment and advance new hypotheses about the origin of this grand phenomenon, which we will further discuss.

Another prototype model, the microspheres, was imagined by Fox. By heating a mixture of amino acids at $180^{\circ} \mathrm{C}$ for 100 hours, in the presence of polyphosphates, the author obtained their non-randomized polymerization into proteinoids (Fox \& Harada, 1958). Placed in hot water and gradually cooled, these proteinoids were aggregated into microscopic globes, which Fox called microspheres. These formations were uniform in size, enriched by environmental proteins, had a double membrane (made up of proteinoids), showed an ultrastructure by electron microscopy, possessed catalytic properties and were capable of dividing by sprouting and fragmentation. The author appreciated that the microspheres were stable structures in the primitive ocean, that they were probably born in lagoons and showed evolutionary potential. At the time of the emergence of protocells, there would have been a pre-genetic system to coordinate their activity, which was not represented by nucleic acids (Fox, 1973).

Microsystems formed on Prebiotic Earth needed protection from the aqueous medium, which favored the hydrolysis reaction. Nature has invented some mechanisms to avoid this risk, such as spiraling biopolymers, formating tertiary structures, but especially generating protocells. Protocells are structures spatially delimited by a membrane that contains genetic information and differs from true cells in that they have not yet developed genomic coded functions (Schrum et al., 2010; Novikov, 2012), systems that preceded living cells that possessed their important features, "but were not yet alive" (Monnard \& Walde, 2015). Their isolation from the environment would be achieved by membrane structures formed by single-chain amphiphiles of fatty acids, which had a high permeability to ions and small molecules (Kitadai \& Maruyama, 2018). Deamer and Oro (1980) considered that Prebiotic Earth had conditions for the synthesis of amphiphilic compounds such as fatty acids, glycerol, glycerol phosphates, acylglycerols, phosphatidic acids, etc., which could be assembled into double membrane vesicles. These structures were stable, osmotically active and probably contributed to the establishment of ionic gradients, the selective absorption of organic compounds and even the appearance of self-replicating systems. The vesicles generated by the fatty acids could increase in two ways: by incorporating the fatty acid micelles and by exchanging fatty acids between the vesicles. As the protocells did not contain complex biological machinery, membranes composed of fatty acids were sufficiently permeable to polar small molecules, ions and even nucleotides. Experimentally, some fatty acid vesicles have been shown to be capable of encompassing DNA and RNA oligonucleotides at temperatures ranging from 0 to $100^{\circ} \mathrm{C}$. Thermal fluctuations could have been a mechanism for separating and recovering double-stranded products resulting from the copying of a polynucleotide chain, and thus genome replication might have begun (Schrum et al., 2010).

Some minerals could catalyze both the assembly of polynucleotides and vesicle membrane by catching the genetic polymer internally in a protocell-like structure. It has been found, for example, that montmorillonite catalyses both RNA polymerization and membrane assembly. Clay particles can provide both RNA synthesis and vesiculation of amphiphiles (Schrum et al., 2010; Kee \& Monnard, 2016). Capillary channels can concentrate fatty acids and cause their self-assembly in the vesicles, but also the concentration of oligonucleotides and their encapsulation in these vesicles, forming spontaneous precellular structures. The coupling of RNA replication with membrane growth would have been an important mechanism in the appearance of protocells and allowed evolution of the Darwinian type. RNA mutations that improved the growth, division and reproduction processes of the protocells implicitly ensured their survival and multiplication in the population through natural selection (Kitadai \& Maruyama, 2018).

In contrast to simple fatty acid membranes, those specific to modern cells contain a mixture of amphiphilic molecules consisting of phospholipids, sterols, other lipids, and various proteins, so their functions have become much more complex (Schrum et al., 2010). The presence of proteins in these structures also ensures selective 
exchanges with solutions from the environment. Protobionts possessed the important attributes of a primitive cell, namely a lipid membrane, a simple metabolism, RNA with catalytic and self-replicating properties that allowed them to detach themselves from the mineral support and live freely (Martin \& Russell, 2007; El Albani et al., 2016). A support for this hypothesis would be the experiments of Sutherland et al. (quoted by Monnard \& Walde, 2015) that demonstrated the common chemical origin of ribonucleotide, amino acid and lipid precursors. "Chemotons" would be the most advanced membrane-bound compartment vesicles, capable of metabolism, autoreproduction and other cellular features, but which could not limit the mutual exchange of genetic information (Monnard \& Walde, 2015).

Excepting viruses, living organisms have the cell as a base unit that performs several functions: metabolism, growth/reproduction, development, chemical communication, evolution. All living organisms have DNA, RNA and proteins in their constitution (the functions of these macromolecules being the same in the living world), they share 3 types of RNA and 34 ribosomal proteins, the genetic code is universal, etc, all these being arguments that they emerge from a common ancestor. According to some paleontological data, the first life forms would be about 3.8-3.9Ga old (after the end of Earth bombing with metorites and comets). As the age of the universal ancestor is approximated to $3 \mathrm{Ga}$, it means that before LUCA, there were more primitive cells that would have evolved through the same mechanisms as modern cells (Rizzotti, 2009).

\section{The Last Universal Common Ancestor of Living Creatures}

The last universal common ancestor (LUCA) of all living organisms on Earth, a term established in 1996, is a theoretical construct, an entity that could or may not be what we now understand to be an organism (Weiss et al., 2018), although there are opinions that it must have been quite complex, not very different from the current forms of life (Monnard \& Walde, 2015). It is assumed that LUCA (also known as the cenancestor or urancestor) was either a cellular individual (whose age was estimated differently by different authors) that had most of the features (implicitly the genes) present in current organisms, or a population of cells endowed with these characters/genes, a population in which there was an intense exchange of genes. In both hypotheses, LUCA was a rather complex entity, which had already undergone a long evolutionary process from the prebiotic stage to the prehistoric stage and had many of the features of current organisms. It produced energy in the form of ATP by generating a proton gradient across the cell membrane (Pascal et al., 2006).

For Woese et al. (1998), the universal ancestor (UA) was not a distinct organism but a process, a community of primitive entities (of progenotes) with small genomic segments in multiple copies, with imprecise information processing systems, simple division, high frequency of mutation and horizontal gene transfer (HGT), etc. The progenote had not fully developed the link between genotype and phenotype (the translation did not reach the potential for generating modern proteins). The progenote contained many linear mini-chromosomes organized in operons, which resembled transposable elements rather than modern chromosomes, chromosomes that were randomly distributed in daughter cells after division. By the horizontal gene transfer, this primitive cell conglomerate (of progenotes) has developed and evolved, the translation process has improved, new proteins have emerged that have perfected metabolic pathways, cellular structures have grown in complexity, cells have gained an higher organization, etc, and ultimately gave birth to a few distinct communities, "which in turn become the three primary lines of descent". The universal ancestor was for Woese "a process characteristic of a particular evolutionary stage," which had "a physical history but not a genealogical one." He added, "Over time, this ancestor has been refined into a smaller number of increasingly complex cell types with the ancestors of the three primary groups of organisms arising as a result", (Woese, 1998).

Studies in comparative genomics and molecular phylogeny have provided evidence of the very ancient origin of cellular processes such as transcription and translation of genetic information, as well as obtaining energy from the proton gradient across membranes. LUCA lived in an active geochemical environment, rich in $\mathrm{H}_{2}, \mathrm{CO}_{2}$ and iron. Its dependence on $\mathrm{CO}_{2}, \mathrm{H}_{2}, \mathrm{CO}$ and nitrogen $\left(\mathrm{N}_{2}\right)$, its affinity for high temperatures and metals, the prevalence of sulphides, the ability to use (but not to generate) ion gradients, are considered as arguments that the living environment of this ancestor would have been alkaline hydrothermal vents. LUCA is described as anaerobic, $\mathrm{CO}_{2}$ fixator, $\mathrm{H}_{2}$-dependent (Wood-Ljungdahl pathway), $\mathrm{N}_{2}$ fixator, and thermophilic (Weiss et al., 2016).

There is controversy over whether LUCA genome was made up of RNA or DNA. Some believe that LUCA genome was probably made up of RNA, and DNA originated from very ancient viral lineage, arguing that there are families of viruses that infect either bacteria, archaea or eukaryotes (Forterre, 2017). It is known, however, that RNA has a high mutation rate, is less stable than DNA, and that the RNA genome cannot exceed a certain size (e.g., up to $30 \mathrm{~kb}$ in current RNA viruses) without serious replication problems (Pascal et al., 2006). The 
LUCA genome would contain over 600 genes (Koonin, 2003) which, in the case of an RNA genome, requires more RNA molecules, which would have created stability problems of the protocells and in their division. Consequently, it is believed that the LUCA genome was probably made up of DNA, and, in this case, several models were advanced. There are still much debated issues. If protobionts had a primitive heredity based on RNA, how was the transition from RNA to DNA effected for the universal ancestor? And if it is admitted that LUCA did not have a DNA genome, the question arises as to how this DNA was formed, on the one hand, on bacteria, on the other hand, on eukaryotes (El Albani et al., 2016). Sequencing the genome of some species of bacteria, archaea and eukaryotes has shown that of the large number of genes specific to these organisms, only about 100 (about 60 others) are common ("universal") and they encode RNAs and proteins involved in translation, ancestral genes which were probably present in the LUCA genome (Koonin, 2003, 2014; Pascal et al., 2006). It should also be noted that, regardless of the size of the genome, the set of genes that code the systems of information processes (primary translation) remained almost unchanged, while genes encoding operational functions had a dynamic evolution (Koonin, 2014).

Was the universal ancestor heterotroph or autotroph? If we admit that life was formed in the "prebiotic soup", then it must have been a heterotroph. If LUCA was a chemolithotrophic organism capable of synthesizing organic molecules from $\mathrm{CO}$ or $\mathrm{CO}_{2}$, obtaining energy from redox reactions involving $\mathrm{H}_{2} \mathrm{~S}, \mathrm{H}_{2}$ and $\mathrm{FeS}$, then it was autotroph. Pascal et al. (2006) feel inclined towards this second hypothesis, arguing that early organisms appeared to be chemolithotrophic organisms with anaerobic respiration, and probably used molecular hydrogen to acquire metabolic energy (such as thermophilic bacteria and current archaebacteria). Some authors suggest that prokaryotes have probably originated from symbiotic "pre-cell" communities through genetic shifts with other structures mediated by transposable elements or viral particles (Barros \& Hoffman, 1985). Comparative genomics studies have shown that a dominant role in prokaryotic evolution has been played by horizontal gene transfer (HGT). The mobilome, a basic component of the prokaryote world, is made up of viruses, plasmids and other selfish elements that have served as HGT vehicles for the exchange of genetic information with more stable chromosomes (Koonin \& Wolf, 2008).

Woese was the supporter of horizontal gene transfer as a factor of species evolution and, in this context, linked the universality of the genetic code to HGT. LUCA was a more evolved entity at the base of the phylogenetic tree, a "Darwinian threshold" that involved the cohesion of cellular lineages. Based on rRNA analysis (small subunit rRNA analysis, a sort of molecular clock), Woese and Fox (1977) established three aboriginal lines of descent: Eubacteria (typical bacteria), Archaebacteria (metanogenic bacteria) and Urkaryotes (the organisms having cytoplasmic components of the eukaryotic cell). They subsequently built a universal phylogenetic tree, a valid representation of the genealogy of organisms. The Bacteria group would be derived directly from LUCA, while Archaea and Eucarya would have a more recent common ancestor than LUCA. For these three groups of organisms, they propose a new taxon called the "domain", a taxon above the kingdoms. The differences between the three groups (domains) are deeper, even larger than those that, for example, separate animals from plants (Woese et al., 1990). This classification was in Woese's "representation of the evolutionary course". Koonin shares Woese's view that LUCA did not yet have a stable cellular organization, being, in some respects, a primitive entity compared to modern cells.

All eukaryotes have in their cells a nucleus (membrane bounded) and mitochondria (cellular power "plants") in their cells, and the plants additionally have chloroplasts (the site of photosynthesis). These cell organites, according to the theory of endosymbiosis, launched in 1967 by Sagan (Margulis), would come from the ingestion of an aerobic bacterium by an ancestral cell in the case of mitochondria, and cyanobacteria in the case of chloroplasts (Ghiorghiță, 2009; Blankenship, 2010; Gray, 2017). Eukaryotes have a chimeric genome, consisting of about $1 / 3$ genes from archaea (genes involved particularly in information processing systems) and about $2 / 3$ genes of bacterial origin (genes that control operational functions) (Koonin, 2014), being therefore a sort of "hybrid" between bacteria and archaea, which shared some membrane, metabolic and genetic properties (El Albany et al., 2016). In the early evolution of cells an important role was played by the phenomenon of gene duplication, which contributed to the emergence of new enzymes, the improvement of the replication and translation machinery, the development of metabolic reactions, etc. (Laczkano \& Miller, 1996).

Forterre (2017) embraces the hypothesis that eukaryotes do not descend directly from the archaea, that they have a common ancestor, and that some of the eukaryotes' attributes existed at LUCA, which were later lost to bacteria and archaeas. The common ancestor of Archaea and Eucarya (last archaeal common ancestor - LACA), was probably a more complex body than archaes, but simpler than eukaryotes. In order to get rid of the protoeukaryote predators, the ancestors of archaeas (and bacteria) invaded high-temperature biotopes, evolving towards a simpler phenotype (thermoreductive hypothesis), while eukaryotes evolved to complexation (using retroviruses and large 
DNA viruses). The thermoreduction hypothesis would also explain the resemblance to some extent of archaeas and bacteria. Although Archaea and Eucarya have a number of molecular features specific to the prokaryotic phenotype, the archaeal mobillome resembles the bacterial one. Even though the term "procaryote" ("before the nucleus") continues to be used in the literature, taking into account progress in molecular phylogeny, Forterre (2013) considers that a more appropriate term for prokaryotes would be "acaryotes".

The first traces of life on Earth (found by isotopic geochemistry) are about 3.8Ga and have been discovered in Greenland and Canada (David, n. d.). The earliest fossils on Earth, the stromatolites-discovered in Warrawoona (Australia), date back to about $3.45 \mathrm{Ga}$ (when the atmosphere of the planet was dominated by $\mathrm{CO}_{2}$ and $\mathrm{N}_{2}$ ) and come from anaerobic cyanobacteria capable of photosynthesis (which hydrogen used to reduce $\mathrm{CO}_{2}$ or $\mathrm{CO}$, probably came from $\mathrm{H}_{2} \mathrm{~S}$ and not from water). Then appeared oxigenic photosynthesis (now about 2.9-2.7Ga), (Bendall et al., 2008; El Albani et al., 2016), in which the hydrogen donor became water, a free oxygen-producing mechanism, first oxidized all the minerals present in the ocean water, after which it began to be released into the atmosphere. In-depth oxygenation of the planetary ocean is dated to about 1.8Ga (Stamati et al., 2011). It is estimated that early Proterozoic (now about $2.5 \mathrm{Ga}$ ) passed from anoxic to oxic atmosphere. Stopping the pyrite and uraninite deposits about $1.8-2 \mathrm{Ga}$ ago and the onset of red continental sedimentation denotes the presence of oxygen in the atmosphere (David, n. d.). The first aerobic organisms, from which current aerobic bacteria would derive, are supposed to be bacteria living around cyanobacterial communities (Rizzotti, 2009). The knowledge gained over time about photosynthesis allows us to assume that on any planetary system in which carbon life exists, photosynthesis (not necessarily oxygen) must also be present (Bendall et al., 2008).

\section{The Appearance and Evolution of MulticellularOrganisms}

Multicelularity occurred in mixobacteria, about $2 \mathrm{Ga}$ ago (Michod, 2007). The transition of unicellular organisms to multicellular organisms implied the development of mechanisms for adherence, recognition, cooperation and communication between cells, their association in precisely co-ordinated tissues, organs and systems. The most widely embraced hypothesis is that multicelularity has emerged from the symbiosis of several unicellular organisms of the same species, which, after division, have not separated each other. This new state of the organism has ensured the increase of its dimensions and complexity, the differentiation of numerous cellular filiations, coordinated cell division, sexual reproduction, etc. (Ghiorghiță, 2017).

In the process of evolution of the living world, eight "major evolutionary transitions" have been identified concerning the increase in biological complexity, including the occurrence of phenomena and events such as genome, chromosomes, genetic code, eukaryotes, gender, differentiated multicellular organisms, colonial superorganisms, human societies (language), (Maynard Smith \& Szathmáry, 1995). More than three billion years ago, monocellular organisms have gradually become increasingly diverse and complex organisms that occupy all living environments (water, soil, atmosphere). The transition from unicellular to multicellular organisms was ensured not only by the acquisition of new genes but also by the interaction of genes, gene duplication (which allowed one of the gene variants to acquire new "tasks"), gene transposition, through mechanisms of gene expression regulation (alternative connection, cis-factors of gene regulation, micro-RNAs, etc.) (Ghiorghiță, 2017).

The acquisition of oxygenic photosynthesis by some organisms has obviously changed life on Earth and determined the use of $\mathrm{O}_{2}$ in respiration. The replacement of fermentation with respiration has led to the development and progress of the living world, has suddenly increased the biosphere productivity, has allowed the evolution and diversification of the animal world (Bendalll et al., 2008; Blankenship, 2010; David, n. d.). If about $2.5 \mathrm{Ga}$ years ago (in Proterozoic) the oxygen level in the atmosphere was low, in late Paleozoic (542-251Ma) its concentration had the highest level ever reached (about 35\%), and in the last 350Ma years, it reached around $21 \%$. Chloroplasts became cellular organites at eukaryotes about $1.25 \mathrm{Ga}$ ago. Enriching the atmosphere in oxygen has significantly increased the efficiency of cellular energy production (about 16-18 times more ATP/hexose molecule) compared to anaerobic metabolism. The superior amount of cellular energy provided by aerobic metabolism has allowed cellular reactions to be diversified (about 1000 times more than in the anaerobic), generating new classes of metabolites. There was also a complex cell partitioning, differentiation of new cell types, etc. In Cambrian, there was a real "explosion" of life on Earth, the diversity of animals peaked, with a double number of phyla than at present (Stamati et al., 2011; David, n. d.; Ghiorghiță, 2017).

The discovery of the Ediacara fauna (Australia) attested that $600 \mathrm{Ma}$ ago Metazoa (the most differentiated living organisms) appeared, and part of the elements of this fauna disappeared after only 56Ma. Burgess Fauna, discovered in several places on Earth, appeared 528Ma ago, then suddenly disappeared after about 20Ma (David, n. d.; Paris, 2016). The first terrestrial plants appeared about 500Ma ago. The bryophytes appeared in Ordovician, 
the first vascular plants in Silurian, the Pteridophytes dominated the terrestrial flora for about $150 \mathrm{Ma}$ (400-250Ma), and, during the secondary era (when the climate became warmer and drier), they left their place to coniferous trees. About 100Ma ago appeared Angiosperms, and at the end of the secondary era, the plants with flowers dominated the planet. In the animal world, placental mammals appeared on Earth 100 to 65Ma years ago, primates about 66Ma years ago, the Hominids about 15-20Ma, and the human group (and of biped ancestors) separated from the chimpanzee group about 7.5-5.6Ma ago. Species of the genus Homo have an age of about $2 \mathrm{Ma}$ and come from East Africa. Homo sapiens, with the earliest human fossils dating from about 200,000 years ago, has its origins here (David, n. d.). The evolution of the living world on Earth culminated with the emergence of man, the most complex being with language, superior thinking, emotions, creativity, etc., which has in its adult body about 37 trillion cells and about 200 different cell types (Stamati et al., 2011; Ghiorghiță, 2017).

The earth has been confronted during its existence with serious biological crises, which involved the mass extinction of some organisms, a phenomenon that has enabled specialists to delimit geological times. About 440Ma ago (end of Ordovician), about one third of the marine fauna (especially trilobites) disappeared. About Ma (end of Devonian) coral reefs were severely affected, which only recovered during the Triasic. The largest biological crisis, however, occurred 245Ma ago (end of Permian), when more than half of the marine organisms and numerous terrestrial vertebrates disappeared ( $90-95 \%$ of the species are estimated to have died). About $65 \mathrm{Ma}$ ago (end of Cretacic), the dinosaurs, rudists, ammonites, and most of the species that lived on the seabed disappeared. The causes of these mass extinctions are little known. If the disappearance of dinosaurs seems to have been the consequence of the effect of a large meteorite falling on Earth, the causes are not very clear in other situations. It is believed that large volcanic eruptions would have produced severe climatic changes that severely affected the living conditions of the organisms that inhabited the planet at that time (David, n. d.).

\section{Conflict of interests}

The authors declare that there is no conflict of interests regarding the publication of this paper.

\section{References}

Arrhenius, J. P. (1903). The propagation of life in space. Die Umschau, 7, 481.

Baaske, P., Weinert, F. M., Duhr, S., Lemke, K. H., Russell, M. J., \& Braun, D. (2007). Extreme accumulation of nucleotides in simulated hydrothermal pore systems. Proc. Natl. Acad. Sci. USA, 104(22), 9346-9351.

Baross, J. A., \& Hoffman, S. E. (1985). Submarine hydrothermal vents ans associated gradient environments as sites for the origin and evolution of life. Origins of Life, 15, 327-345.

Bendall, D. S., Howe, C. J., Nisbet, E. G., \& Nisbet R. E. (2008). Introduction. Photosynthetic and atmospheric evolution. Philos. Trans. R. Soc. Lond. B Biol. Sci., 363(1594), 2625-2628.

Bernstein, M. (2006). Prebiotic materials from on and off the early Earth. Philos. Trans. R. Soc. Lond. B Biol. Sci., 361(1474), 1689-1702.

Blankenship, R. E. (2010). Early evolution of photosynthesis. Plant Physiol., 154(2), 434-438.

Brack, A. (1991). The origin of life on Earth. Grana, 30, 505-509.

Cleaves, H. J. (2012). Prebiotic chemistry: What we know, what we don't. Evolution, Education and Outreach, 5 , 443.

Corliss, J. B., Baross, J. A., \& Hoffmann, S. E. (1981). An hypothesis concerning the relationship between submarine hot spring and the origin of life on Earth. Oceanol. Acta, 4, 59-69.

Crick, F. H. C., \& Orgel, L. E. (1973). Directed panspermia. ICARUS, 19, 341-346.

David, F. (n. d.). Les grandes étapes de l'histoire du vivant. ACCES INRP. Retrieved from http://acces.ens-lyon.fr/acces/thematiques/biodiversite/dossiers-thematiques/les-trois-domains-du/vivant

Deamer, D. W., \& Oro, J. (1980). Role of lipids in prebiotic structures. Biosystems, 12(3-4), 167-175.

Deamer, D., Singaram, S., Rajamani, S., Kompanichenko, V., \& Guggenheim, S. (2006). Self-assembly processes in the prebiotic environment. Philos. Trans. R. Soc. Lond. B. Biol. Sci., 361(1474), 1809-1818.

El Albani, A., Macchiarelli, R., \& Meunier, A. (2016). Aux origines de la vie. Une nouvelle histoire de l'évolution. Ed. Dunod, 221.

Forterre, P. (2013). The common ancestor of Archaea and Eucarya was not an Archaeon. Archaea, 11, 372396.

Forterre, P. (2017). LUCA our common ancestor. Retrieved from https://news.cnrs.fr/opinions/luca-our-common -ancestor 
Fox, S. W. (1973). Molecular evolution to the first cells. Pure Appl. Chem., 34(3), 641-669.

Fox, S. W., \& Harada, K. (1958). Thermal copolymerization of amino acids to a product resembling protein. Science, $128(3333), 1214$.

Fox, S. W., \& Harada, K. (1961). Synthesis of uracil under conditions of a thermal model of prebiological chemistry. Science, 133, 1923-1924.

Garrison, W. M., Morrison, D. C., Hamilton, J. G., Benson, A. A., \& Calvin, M. (1951). Reduction of carbon dioxide in aqueous solutions by ionizing radiation. Science, 114, 416-418.

Ghiorghiță, I. G. (2009). Despre biogeneză și bioevoluție (p. 186). Ed. ”Alma Mater”, University of Bacău.

Ghiorghiță, I. G. (2017). Some considerations on the transition from unicellular to multicellular life. An. Șt. Univ. ”Al. I. Cuza", Iași, Ser. Genetică și Biol. Mol., 18(2), 47-58.

Gray, M. W. (2017). Lynn Margulis and the endosimbiont hypothesis: 50 years later. Mol. Biol. Cell, 28(10), 1285-1287.

Haldane, J. B. S. (1929). Origin of life. The Rationalist Annual, 148, 3-10.

Herschy, B., Whicher, A., Camprubi, E., Watson, C., ..., \& Lane N. (2014). An origin-of-Life reactor to simulate alkaline hydrothermal vents. J. Mol. Evol., 79(5-6), 213-227.

Kee, T. P., \& Monnard, P. A. (2016). On the emergence of proto-metabolism and the assembly of early protocells. Elements, 12(6), 419-424.

Kitadai, N., \& Maruyama, S. (2018). Origins of building bloks of life: A review. Geoscience Frontiers, 9(4), 117-1153.

Kobayashi, K., Kaneko, T., Ponnamperuma, C., Oshima, T., Yanagawa, H., \& Saito, T. (1997). Abiotic synthesis of bioorganic compounds in simulated primitive planetary environments. Nippon Kagaku Kaishi, 12.

Kobayashi, K., Oshima, T., \& Yanagawa, H. (1989). Abiotic synthesis of amino acids by proton irradiation of a mixture of carbon monoxide, nitrogen, and water. Chemistry Letters, 18(9), 1527-1530.

Kobayashi, K., Tsuchia, M., Oshima, T., \& Yanagawa, H. (1990). Abiotic synthesis of amino acids and imidazole by proton irradiation of simulated primitive earth atmosphere. Origins of Life and Evolution Biospheres, 20(2), 99-109.

Kolb, V. M. (2015). Oparin's coacervates as an important milestone in chemical evolution. Proceed. of the SPIE, 9606.

Koonin, E. V. (2003). Comparative genomics, minimal gene-sets and the last universal common ancestor. Nat. Rev. Microbiol., 1, 127-136.

Koonin, E. V. (2014). Carl Woese's vision of cellular evolution and the domanins of life. RNA Biol., 11(3), 197-204.

Koonin, E. V., \& Wolf, Y. I. (2008). Genomics of bacteria and archaea: The emerging dynamic view of the prokaryotic world. Nucleic Acids Res., 36(21), 6688-6719.

Kremp, G. O. W. (1982). The oldest traces of life and the advancing organization of the Earth. Part I: Archaean and Cryptophytic. Paleo Data Banks. Univ. of Arizona, 18.

Laczkano, A., \& Bada, J. L. (2003). The 1953 Stanley L. Miller experiment: Fifty years of prebiotic organic chemistry. Origins of Life and Evolution of Biosphere, 33(3), 235-242.

Lambert, J. F. (2015). Origins of life: From the mineral to the biochemical world. BIO Web of Conferences, 4, 00012. EDP Sciences.

Luminet, J. P. (2014). 100 questions sur l'Univers (p. 224). Éd. La Boétie.

Mader, S. (1990) Biology. Part 3: Evolution and diversity. Wm C. Brown Publishers.

Martin, W., \& Russell, M. J. (2003). On the origins of cells: A hypothesis for the evolutionary transitions from abiotic geochemistry to chemoautotrophic prokariotes, and from prokaryotes to nucleated cells. Philos. Trans. R. Soc. Lond. B. Biol. Sci., 358, 1429, 59-85.

Martin, W., \& Russell, M. J. (2007). On the origin of biochemistry at an alkaline hydrothermal vent. Phil. Trans. R. Soc. B., 362, 1887-1925. 
Martin, W., Baross, J., Kelley, D., \& Russell, M. J. (2008). Hydrothermal vents and the origin of life. Nature Rev., Microbiol., 6, 805-814.

Maury, C. P. J. (2018). Amyloid and the origin of life: Self-replicating catalytic amyloids as prebiotic informational and protometabolic entities. Cell Mol. Life Sci., 75(9), 1499-1507.

Maynard Smith, J., \& Szathmáry, E. (1995). The major transitions in evolution. Nature, 374. Freeman, Oxford.

Michod, E. R. (2007). Evolution of individuality during the transition from unicellular to multicellular life. Proceed. Nat. Acad. Sci. USA., 104(1).

Miller, S. L. (1974). The atmosphere of the primitive Earth and the prebiotic synthesis of amino acids. Origins of life, 5(1-2), 139-151.

Monnard, P. A., \& Walde, P. (2015). Current ideas about prebiological compartmentalization. Life (Basel), 5(2), 1239-1263.

Neuville, S. (2018). Prebiotic mechanisms of life appearance near deep sea vents with early Earth synthetized L-handed amino-acids being adsorbed on SWCNT. Quarterly Physics Review, 4(2), 1-36.

Novikov, V. P. (2012). Three-stage origin of life as a result of directional darwinian evolution. Other Quantitative Biol. Cornell Univ., 10.

Oparin, A. I. (1924). Proiskhozhdenie zhizni. Izd. Moskovskii rabochii, Moskva.

Oparin, A. I. (1960). Originea vieții pe Pământ (p. 475). Ediția a III-a. Ed. ”Științifică”, București.

Oro, J., \& Kimball A. P. (1961a). Synthesis of purines under possible primitive Earth conditions. II. Purine intermediates from hydrogen cyanide. Arch. Biochem. Biophys., 96, 293.

Oro, J., \& Kimball, A. P. (1961b). Synthesis of purines under possible primitive Earth conditions. I. Adenine from hydrogen cyanide. Arch. Biochem. Biophys., 94, 217.

Paris, R. (2016). Burges, Ediacara, deux plus grandes révolutions des espèces vivantes. Retrieved from http://www.matiereevolution.fr/spip.php?article3959

Pascal, R. T., Boiteau, L., Forterre, P., Gargaud, M., ..., \& Reisse, J. (2006). Prebiotic chemistry-Biochemistry-Emergence of Life (4.4-2Ga). Earth, Moon, and Planets, 98, 153-203.

Rizzotti, M. (2009). The earliest anaerobic and aerobic life. Biol. Sci. Fund. And Syst., EOLSS, 1, 212-230.

Russell, M. J., Daniel, R. M., Hall, A. J., \& Sherringham, J. (1994). A hydrothermally precipitated catalytic iron sulphide membrane as a first step toward life. J. Mol. Evol., 39, 231-243.

Schrum, J. P., Ting, F., Zhu, T. F., \& Szostak, J. W. (2010). The origins of cellular life. Cold Spring Harb. Perspect. Biol., 2(9).

Stamati, K., Mudera, V., \& Cheema, U. (2011). Evolution of oxygen utilization in multicelluar organisms and implications for cell signalling in tissue engineering. J. Tissue Eng., 2(1), 2041731411432365.

Surpateanu, G. (2018). Syntone chemistry and prebiotic stage in life evolution 1. Aziridinone, a key compound in formation of the first proteinogenic amino acids and polypeptides. Int. J. of Astrobiol., 17(4), 361-379.

Surpateanu, G., \& Lungu, N. C. (2011). Chemical behaviour of methylene in the presence of ammonia, carbon dioxide and water. Rev. Chim. Bucharest, 62, 1107-1110.

Tirard, J. B. S. (2017). Haldane and the origin of life. J. of Genetics, 96(5), 735-739.

Trefil, J., Morowitz, H. J., \& Smith, E. (2009). The origin of life. American Scientist, 97(3), 206.

Weiss, A. C., Preiner, M., Xavier, J. C., Zimorski, V., \& Martin, V. F. (2018). The last universal common ancestor between ancient Earth chemistry and the onset of genetics. PLOS Genetics.

Weiss, M. C., Sousa, F. L., Mrnjavac, N., Neukirchen, S., ..., \& Martin, W. F. (2016). The physiology and habitat of the last universal common ancestor. Nature Microbiol., 1(9).

Woese, C. R. (1979). A proposal concerning the origin of life on the planet Earth. J. Mol. Evol., 13, 95-101.

Woese, C. R. (1998). The universal ancestor. Proc. Natl. Acad. Sci. USA, 95(12), 6854-6859.

Woese, C. R., \& Fox, G. E. (1977). Phylogenetic structure of the procaryotic domain: The primary kingdoms. Proc. Natl. Acad. Sci. USA, 74(11), 5088-5090. 
Woese, C. R., Dugre, D. H., Saxinger, W. C., \& Dugre, S. A. (1966). The molecular basis for the genetic code. Proc. Natl. Acad. Sci. USA, 55(4), 966-974.

Woese, C. R., Kandler, O., \& Wheelis, M. L. (1990). Towards a natural system of organisms: Proposal for the domains Archaea, Bacteria, and Eucarya. Proc. Natl. Acad. Sci. USA, 87, 4576-4579.

\section{Copyrights}

Copyright for this article is retained by the author(s), with first publication rights granted to the journal.

This is an open-access article distributed under the terms and conditions of the Creative Commons Attribution license (http://creativecommons.org/licenses/by/4.0/). 